\title{
VARIATIONS IN FATTY ACID PROFILES, OIL AND MOISTURE CONTENT DURING FRUIT RIPENING IN OIL PALM CROSSES GROWN IN INDIA UNDER SUB-TROPICAL ENVIRONMENT
}

\author{
SURESH, $K^{*}$ and SANJIB KUMAR BEHERA**
}

\begin{abstract}
During fruit ripening, a sequence of physical and chemical transformations takes place in oil palm fruits. The study elucidated variations in fruit weight, oil content in mesocarp and fatty acid profiles during fruit ripening at 12, 14, 16, 18, 20 weeks after anthesis (WAA) of four commercial oil palm crosses viz., United Plantations (UP), Deli $x$ Nigeria $(D x N)$, Palode and Deli $x$ Ghana $(D x G)$ under sub-tropical environment. Fruit weight (5.4 g-10.6 g) and oil content (22.6\%-79.9\%) in crosses increased from 12-20 WAA. The ideal time of harvest was at 20 WAA, which coincided with highest oil content. The moisture content in mesocarp decreased as fruit ripened. Six fatty acid profiles viz., myristic $(0.5 \%-2.1 \%)$, palmitic $(31.1 \%$ $45.1 \%)$, stearic $(2.8 \%-5.1 \%)$, oleic $(19.1 \%-43.1 \%)$, linoleic $(8.7 \%-32.4 \%)$ and linolenic $(0.4 \%-10.4 \%)$ were identified by standardising gas chromatograph parameters. Monounsaturated fatty acids (MUFA) and saturated fatty (SFA) acids increased in all crosses as fruits ripened from 12-20 WAA, while polyunsaturated fatty acids decreased during ripening. Monounsaturated and polyunsaturated fatty acids were highest in DxG cross, indicating its better oil quality. Variations in fatty acid profiles of oil palm crosses can be utilised for developing palms with superior oil quality.
\end{abstract}

\section{Keywords: fatty acid composition, fruit weight, gas chromatography, oil content, oil quality, oil palm, ripening.}

Date received: 11 March 2019; Sent for revision: 28 March 2019; Accepted: 22 November 2019.

\section{INTRODUCTION}

Oil palm is an introduced crop in India, which is known for high oil yield (4-6 $\mathrm{t}$ oil ha $\mathrm{har}^{-1} \mathrm{yr}^{-1}$. Various committees constituted by the government of India have identified an area of 1.933 million hectares as potential for oil palm cultivation in different Indian provinces (Arulraj and Narasimha Rao, 2012). To date, an area of 0.331 million hectares is under oil palm cultivation in India grown under sub-tropical conditions. The fruit of oil palm is known as drupe, consisting of exocarp, mesocarp and endocarp. The mesocarp of fruit is fleshy and is a source of crude palm oil (CPO). Kernel oil is obtained from the

\footnotetext{
* ICAR-Indian Institute of Oil Palm Research, Pedavegi-534 450, Andhra Pradesh, India. E-mail: sureshkancherla@rediffmail.com

** ICAR-Indian Institute of Soil Science, Bhopal - 462 038, Madhya Pradesh, India.
}

endocarp of fruit, which is used in different forms by the industry. The biological processes in plants during reproductive phase like development of fruit, maturation and ripening are quite unique. Oil formation and its constitution during fruit ripening process have been a topic of discussion for physiologists and plant breeders of oil palm fraternity. There have been some reports of lipid composition in oil palm under tropical conditions (Bafor and Osagie, 1986; Noh et al., 2002; Sundram et al., 2003; Prada et al., 2011; Aung et al., 2018; Zaliha et al., 2018). The biochemical changes in oil palm during storage have been extensively studied (Salini et al., 1999). Understanding the biochemical and physiological changes during water stress could aid in developing crosses/hybrids possessing higher yield and better oil quality (Yordanov et al., 2000).

The knowledge of fatty acid composition in oil palm plays a pivotal role in understanding chemical and physical properties of oil, which helps in 
determining the optimum time of harvest. The oil synthesis has been understood from accumulation of triacylglycerols during process of ripening under tropical conditions (Bates et al., 2009; Baud and Lepiniec, 2010). Many fatty acids that cannot be synthesised by human body could be derived from CPO (Sambanthamurthi et al., 2000; Solomons and Orozco, 2003). The proportion of unsaturated to saturated fatty acids plays a vital role in nutrition of human beings (Ganesan et al., 2018). There is a lot of demand for high oleic fatty acid plants in the food industry due to its tolerance to oxidation (Indelicato et al., 2017; Redondo-Cuevas et al., 2018). Palm oil seems to be oxidatively stable among the vegetable oils due to its equal proportions of unsaturated and saturated fatty acids (Ebong et al., 1999; Basiron, 2005). Palm oil and palm kernel oil are the predominant vegetable oils in food industry (Okechalu et al., 2011).

The expression of genes linked to biosynthesis of triacylglycerol and fatty acid along with its heritability have been explored by various authors (Montoya et al., 2014; Zulkifli et al., 2014; Ting et al., 2016). The fatty acid composition of oils from $F_{1}$ generation of Elaeis oleifera $\times$ Elaeis guineensis interspecific hybrids is normally intermediary between their parents, while fatty acid content in $\mathrm{F}_{2}$ generation exhibits the composition of $\mathrm{F}_{1}$, which is attributed to additive heredity and co-dominance in hybrids. The differences in fatty acid content between oils from African and hybrid palms could be related to the expression of genes encoding $\beta$-ketoacyl-ACP synthase (KAS) II, which is specifically used for chain lengthening of C16:0 to C18:0 (Mozzon et al., 2013; Lieb et al., 2017).

Different quantitative trait loci (QTL) for fatty acids and iodine value have been identified and a few structural genes encoding the enzymes involved in de novo synthesis of fatty acids and triacylglycerol assembly have been localised in genomic intervals (Jin et al., 2017; Lieb et al., 2017). The activity of $\Delta 12$ fatty acid desaturase from oil palm has been tested in yeast, and it produced about $12 \%$ of linoleic acid, which barely existed in wild yeast cells (Sun et al., 2016). The first $\omega-3$ fatty acid desaturase (involved in biosynthesis of alpha-linolenic acid) gene has been identified and characterised from oil palm (Chen et al., 2018).

There has been no information on alterations in fatty acid composition in oil palm under sub-tropical conditions and most of the work has been reported under tropical rainforest environments (Noh et al., 2002; Sundram et al., 2003; Prada et al., 2011; Aung et al., 2018; Zaliha et al., 2018). The oil content along with fatty acid profile during fruit ripening can differ both quantitatively and qualitatively under different environmental situations. Breeding programmes are generally targeted for higher unsaturated fatty acid composition present in Elaeis oleifera for achieving better oil quality (Opute, 1979).

Since knowledge about chemical and physical alterations in fatty acid composition during ripening process under sub-tropical conditions is not available, this study has been taken up, which would also help in understanding ideal harvest index in oil palm. Furthermore, a master plan could be drafted for evolving oil palm crosses possessing altered fatty acid profile and high oil content. In this context, the study is mainly intended to document alterations in fatty acid profile, fruit weight, oil and moisture content in four commercial oil palm tenera crosses grown under sub-tropical environment.

\section{MATERIALS AND METHODS}

The study was conducted at the Indian Institute of Oil Palm Research, Pedavegi, Andhra Pradesh, India, in four adult oil palm tenera crosses namely Deli $x$ Nigeria $(D x N)$, Palode, Deli $x$ Ghana $(D x G)$ and United Plantations (UP). The four crosses selected were locally grown, which varied morphologically in terms of height, girth and yield. Pedavegi is situated at $16^{\circ} 8^{\prime} \mathrm{N}, 81^{\circ} 11^{\prime} \mathrm{E}$ with a mean sea level of $13.4 \mathrm{~m}$. The palms were planted with $9 \mathrm{~m}$ triangular spacing and standard agronomic practices were followed. The weather at experimental site is a typical sub-tropical one. The mean minimum and maximum temperature varied from $18.9^{\circ} \mathrm{C}-28.3^{\circ} \mathrm{C}$ and $32.8^{\circ} \mathrm{C}-39.6^{\circ} \mathrm{C}$, respectively. The relative humidity was in the range of $34.2 \%-99.2 \%$ and 925 $\mathrm{mm}$ rainfall was received during the period.

The inflorescences were tagged at the time of anthesis and five stages [12, 14, 16, 18 and 20 week after anthesis (WAA)] were monitored for different parameters from 12- 20 WAA at weekly intervals. Nine inflorescences were selected for a cross at each stage making the total inflorescences to 45 during the study. In total, 180 inflorescences were evaluated for fruit weight, moisture and oil content along with fatty acid profiles at five stages in the four crosses studied.

The fruit weight, oil and moisture content in fruits of different crosses were done by undertaking bunch analysis as per Blaak (1963) and Prada et al., (2011). The bunch was harvested at each stage and outer and inner fruits were separated. The mean of outer and inner fruits gave average fruit weight, which is expressed in grams. The moisture content in fruits was estimated by taking a sample of outer and inner fruits. Fresh weights of these fruits were taken and mesocarp was scrapped. Later it was dried in an oven at $105^{\circ} \mathrm{C}$ for $24 \mathrm{hr}$ and dry weights were recorded. Triplicates of samples were taken to minimise sampling error. Oil content was estimated by gravimetric method. Dry mesocarp 
samples were ground and $5 \mathrm{~g}$ of sample were kept in a small container and petroleum ether was used as a solvent in a soxhlet extractor at $60^{\circ} \mathrm{C}-80^{\circ} \mathrm{C}$ for 24 hr. Ten to 15 samples were estimated for oil content simultaneously in the extraction unit.

The fatty acid composition was determined as per Morrison and Smith (1964). Conversion of oil to fatty acid methyl esters (FAME) was done by adding $5 \mathrm{ml}$ of sodium methoxide $(0.1 \mathrm{~N}$ in methanol) and $1 \mathrm{ml}$ hexane in the oil solution. The solution was stirred vigorously using vortex stirrer for $10 \mathrm{~s}$ and left to separate, till a clear solution is obtained. The aqueous layer was collected by using micropipette and transferred into eppendorf tubes, which were directly injected into gas chromatography (Model GC 17A, Shimadzu Corporation, Kyoto, Japan). The model is well equipped with flame ionisation detector (FID) and a polar capillary column BPX 70 $(60 \mathrm{~m} \times 0.25 \mathrm{~mm} \times 0.25 \mu \mathrm{m})$. The column, injector and FID were set at $180^{\circ} \mathrm{C}, 230^{\circ} \mathrm{C}$ and $250^{\circ} \mathrm{C}$. Column

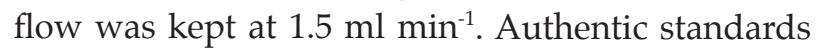
stored at $4^{\circ} \mathrm{C}$ were used under similar conditions as that of FAME which were identified by mean of retention times. The samples were compared with those of standard FAME.

Statistical analysis was done using MSTAT statistical software (MSTAT developed at the Department of Crop and Soil Science, Michigan State University, USA).

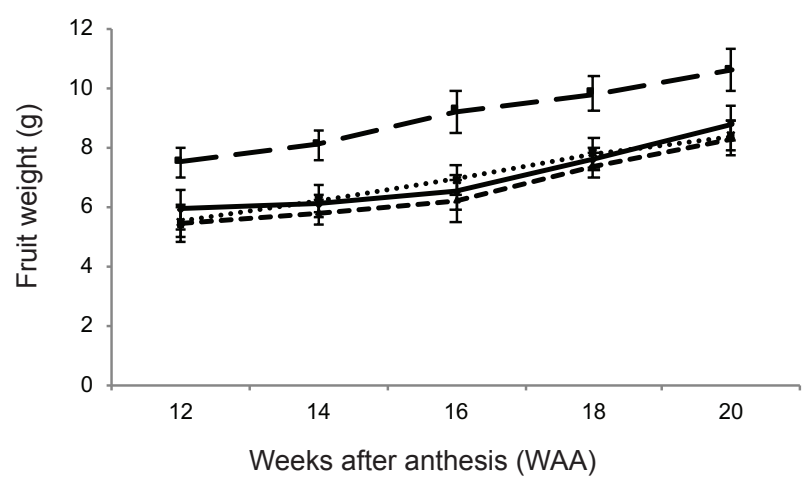

\section{RESULTS AND DISCUSSION}

The fruit weight of oil palm crosses during the process of ripening (12-20 WAA) ranged from $5.4 \mathrm{~g}-10.6 \mathrm{~g}$ (Figure 1). Palms of UP possessed the maximum fruit weight (10.6 g) at maturity (20 WAA), followed by palms of DxG and DxN. The fruit weight was lowest in palms of Palode cross at 20 WAA. In palms of all the crosses, fruit weight increased from 12-20 WAA. There was no conclusive trend in fruit weight among oil palm crosses and could be inferred that biochemical changes could have been only occurred in the mesocarp of fruit (Prada et al., 2011). The palms of all the crosses recorded highest fruit weight at 20 WAA indicating its ideal time of harvest, which is consistent with the findings of Prada et al. (2011) and Alvarado and Sterling (1998). The fruit ripening in a bunch starts from top to bottom portion and spreads from outer to inner fruits of spikelets (Kaida, 1992). The maturity of bunch in oil palm could be affected by changes in environment (Azis, 1985).

A perusal of data (Figure 1) relating to oil content in the mesocarp of fruits of different crosses indicated that it ranged from $22.6 \%-79.9 \%$ (12-20 WAA). The oil content was less till 16 WAA in fruits of all the crosses and increased sharply from 18 WAA onwards. The highest oil content was recorded at 20 WAA in fruits of all crosses. The fruits of DxG possessed maximum oil content followed by fruits of Palode and UP. The oil accumulation in mesocarp of oil palm fruits was

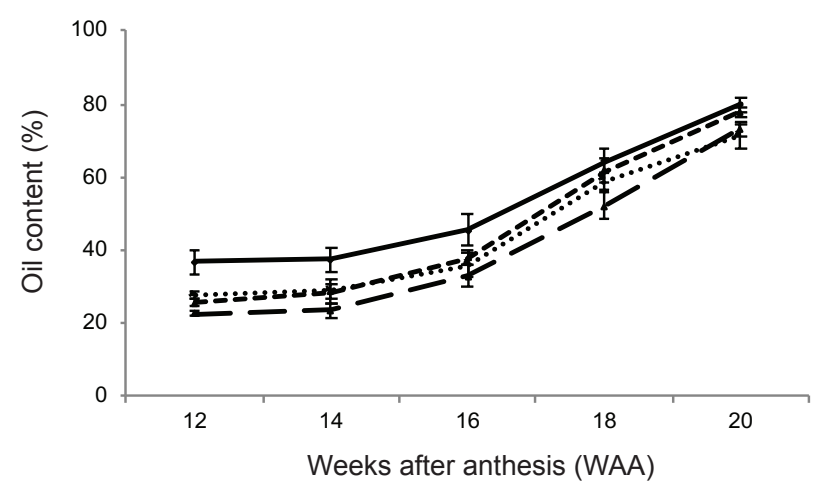

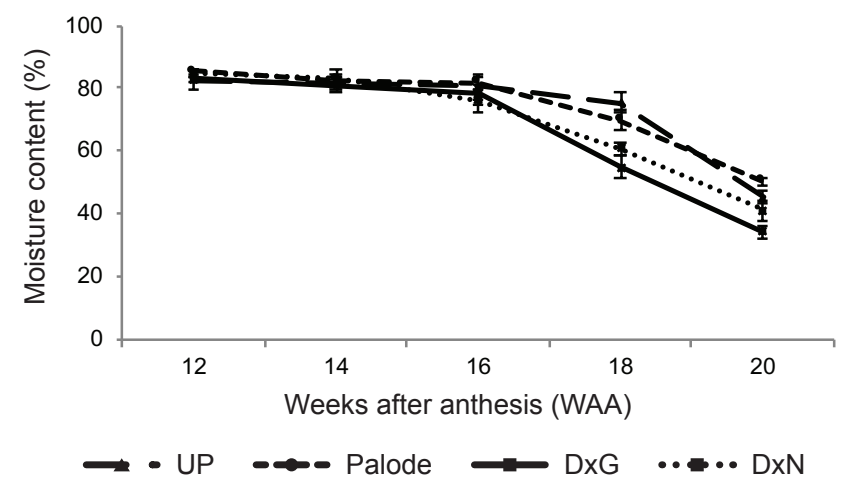

Figure 1. Variations in fruit weight $(\mathrm{g})$, oil and moisture content $(\%)$ at different stages of ripening process in oil palm crosses [bars depict standard deviation of mean $(n=9)]$. 
at $20^{\text {th }}$ week after anthesis (Oo et al., 1986; Suresh et al., 2013). Environmental factors play an important role in influencing fruit set and oil content in oil palm (Corley and Tinker, 2003). Variations in oil content in oil palm crosses could be also due to genetic and environmental factors (Bafor and Osagie, 1986).

The moisture content in mesocarp of fruits showed decreasing trend during ripening process (12-20 WAA) in all the four crosses studied (Figure 1 ). The moisture content during ripening process decreased from $84.5 \%$ to $41.1 \%$ in $\mathrm{DxN} ; 82.8 \%-34.3 \%$ in DxG; $82.6 \%-45.3 \%$ in UP and $85.2 \%-50.3 \%$ in Palode cross. The decrease in moisture content in fruits was more during 18-20 WAA due to rapid accumulation of oil in the mesocarp, which are consistent to the findings of some workers (Oo et al., 1985; Bafor and Osagie, 1986).

Fatty acid composition in different oil palm crosses during 12-20 WAA is depicted in Table 1. Six different fatty acids viz., myristic, palmitic, stearic, oleic, linoleic and linolenic acid were analysed during the study. Myristic acid in the fruits of different crosses during ripening varied from $0.5 \%-21 \%$ and its content increased with the process of ripening. Fruits of UP recorded the highest palmitic acid followed by fruits of Palode cross. The content of palmitic acid increased during the process of ripening and it ranged from $31.1 \%-45.1 \%$ in different crosses. Stearic acid content in oil palm crosses was in the range of $2.8 \%-5.1 \%$ during ripening process. The contents of oleic, linoleic and linolenic fatty acids during ripening process ranged in the order of $19.1 \%-43.1 \%$, $32.4 \%-8.7 \%$ and $10.4 \%-0.4 \%$ respectively, among the different oil palm crosses studied. The fatty acid contents obtained in this study are similar to findings obtained in oil palm (Rincon and Martinez, 2009). Among the fatty acid profiles, myristic, palmitic, stearic and oleic acids showed increasing trend

TABLE 1. VARIATIONS IN FATTY ACID COMPOSITION (\%) DURING DIFFERENT STAGES OF FRUIT RIPENING PROCESS IN OIL PALM CROSSES $(\mathrm{n}=9)$

\begin{tabular}{|c|c|c|c|c|c|c|}
\hline WAA & $\begin{array}{l}\text { Myristic acid } \\
\text { (C:14:0) }\end{array}$ & $\begin{array}{l}\text { Palmitic acid } \\
\quad(C: 16: 0)\end{array}$ & $\begin{array}{l}\text { Stearic acid } \\
\text { (C:18:0) }\end{array}$ & $\begin{array}{l}\text { Oleic acid } \\
\text { (C:18:1) }\end{array}$ & $\begin{array}{l}\text { Linoleic acid } \\
\text { (C:18:2) }\end{array}$ & $\begin{array}{c}\text { Linolenic acid } \\
\text { (C:18:3) }\end{array}$ \\
\hline \multicolumn{7}{|c|}{ United Plantations (UP) } \\
\hline 12 & $1.0 \pm 0.2$ & $33.7 \pm 1.8$ & $3.2 \pm 0.4$ & $20.4 \pm 2.1$ & $28.1 \pm 1.6$ & $8.2 \pm 0.3$ \\
\hline 14 & $1.0 \pm 0.1$ & $38.2 \pm 1.6$ & $3.4 \pm 0.3$ & $28.4 \pm 1.6$ & $20.4 \pm 1.6$ & $4.1 \pm 0.2$ \\
\hline 16 & $1.1 \pm 0.2$ & $42.7 \pm 1.4$ & $3.8 \pm 0.4$ & $34.1 \pm 1.8$ & $15.4 \pm 1.4$ & $2.4 \pm 0.1$ \\
\hline 18 & $1.1 \pm 0.3$ & $44.1 \pm 1.2$ & $4.6 \pm 0.3$ & $35.9 \pm 1.7$ & $10.2 \pm 1.4$ & $1.7 \pm 0.1$ \\
\hline 20 & $1.4 \pm 0.2$ & $45.1 \pm 1.1$ & $4.1 \pm 0.2$ & $40.1 \pm 2.1$ & $8.7 \pm 0.8$ & $0.4 \pm 0.1$ \\
\hline \multicolumn{7}{|c|}{ Palode } \\
\hline 12 & $0.5 \pm 0.1$ & $34.1 \pm 1.1$ & $3.0 \pm 0.2$ & $19.6 \pm 1.1$ & $30.1 \pm 0.9$ & $9.1 \pm 0.4$ \\
\hline 14 & $0.5 \pm 0.1$ & $37.9 \pm 1.4$ & $3.7 \pm 0.3$ & $26.4 \pm 2.1$ & $24.3 \pm 1.4$ & $2.5 \pm 0.2$ \\
\hline 16 & $0.9 \pm 0.2$ & $40.5 \pm 1.6$ & $4.0 \pm 0.4$ & $32.1 \pm 2.2$ & $17.8 \pm 1.6$ & $2.8 \pm 0.3$ \\
\hline 18 & $0.9 \pm 0.2$ & $42.2 \pm 1.2$ & $5.0 \pm 0.4$ & $35.6 \pm 1.7$ & $11.4 \pm 1.3$ & $1.4 \pm 0.1$ \\
\hline 20 & $1.8 \pm 0.3$ & $44.6 \pm 1.0$ & $5.1 \pm 0.5$ & $36.6 \pm 1.4$ & $10.2 \pm 1.4$ & $0.6 \pm 0.1$ \\
\hline \multicolumn{7}{|c|}{ Deli x Ghana (DxG) } \\
\hline 12 & $0.8 \pm 0.1$ & $31.1 \pm 0.9$ & $2.8 \pm 0.2$ & $21.7 \pm 0.7$ & $31.4 \pm 0.8$ & $10.4 \pm 0.5$ \\
\hline 14 & $0.6 \pm 0.1$ & $34.5 \pm 1.5$ & $3.3 \pm 0.1$ & $27.3 \pm 2.1$ & $25.6 \pm 1.8$ & $4.3 \pm 0.3$ \\
\hline 16 & $1.0 \pm 0.2$ & $36.4 \pm 1.6$ & $3.5 \pm 0.4$ & $38.4 \pm 1.8$ & $16.2 \pm 1.6$ & $2.1 \pm 0.2$ \\
\hline 18 & $1.0 \pm 0.2$ & $38.1 \pm 1.8$ & $4.5 \pm 0.3$ & $42.7 \pm 2.2$ & $11.7 \pm 1.7$ & $1.2 \pm 0.2$ \\
\hline 20 & $1.3 \pm 0.2$ & $39.4 \pm 1.5$ & $4.7 \pm 0.5$ & $43.1 \pm 1.6$ & $10.5 \pm 1.6$ & $0.4 \pm 0.1$ \\
\hline \multicolumn{7}{|c|}{ Deli x Nigeria $(\mathrm{DxN})$} \\
\hline 12 & $0.7 \pm 0.1$ & $32.4 \pm 1.1$ & $3.3 \pm 0.2$ & $19.1 \pm 1.1$ & $32.4 \pm 1.0$ & $8.7 \pm 0.4$ \\
\hline 14 & $0.8 \pm 0.1$ & $40.8 \pm 1.2$ & $3.2 \pm 0.2$ & $28.3 \pm 2.1$ & $23.8 \pm 0.7$ & $2.8 \pm 0.3$ \\
\hline 16 & $0.6 \pm 0.1$ & $42.4 \pm 1.1$ & $4.9 \pm 0.4$ & $31.2 \pm 1.4$ & $17.3 \pm 1.1$ & $2.2 \pm 0.3$ \\
\hline 18 & $1.0 \pm 0.1$ & $44.6 \pm 1.4$ & $4.6 \pm 0.4$ & $34.5 \pm 1.6$ & $11.4 \pm 1.4$ & $1.3 \pm 0.2$ \\
\hline 20 & $2.1 \pm 0.2$ & $43.1 \pm 1.6$ & $5.1 \pm 0.5$ & $38.4 \pm 1.8$ & $10.7 \pm 1.4$ & $0.4 \pm 0.1$ \\
\hline
\end{tabular}

Note: Mean \pm standard deviation $(n=9)$, WAA - weeks after anthesis. 
during process of fruit ripening, while linoleic and linolenic fatty acids decreased as the fruits ripened.

The six fatty acids analysed during the process of ripening could be classified as monounsaturated fatty acids, [MUFA (oleic acid)], polyunsaturated fatty acids, [PUFA (linoleic and linolenic acids)] and saturated fatty acids, [SFA (myristic, palmitic and stearic acids)]. Among the oil palm crosses studied, SFA was the highest contributor to total fatty acid composition followed by MUFA and PUFA (Figure 2). Fruits of DxG cross possessed the highest MUFA + PUFA content, which was closely followed by fruits of DxN and UP cross. The lowest content of MUFA + PUFA was recorded in fruits of Palode cross. Conversely, SFA content was highest in fruits of Palode cross followed by fruits of UP and DxN. MUFA and SFA contents in all crosses increased during the process of ripening (14-20 WAA), while PUFA content decreased as fruits matured. Similar variations in fatty acid composition were observed in different oil palm hybrids (Rajanaidu and Tan, 1983; Prada et al., 2011). The fatty acid composition at various stages of fruit ripening indicated that major alterations are occurring in oleic, palmitic and linolenic acids (Bafor and Osagie, 1986; Oo et al., 1986;

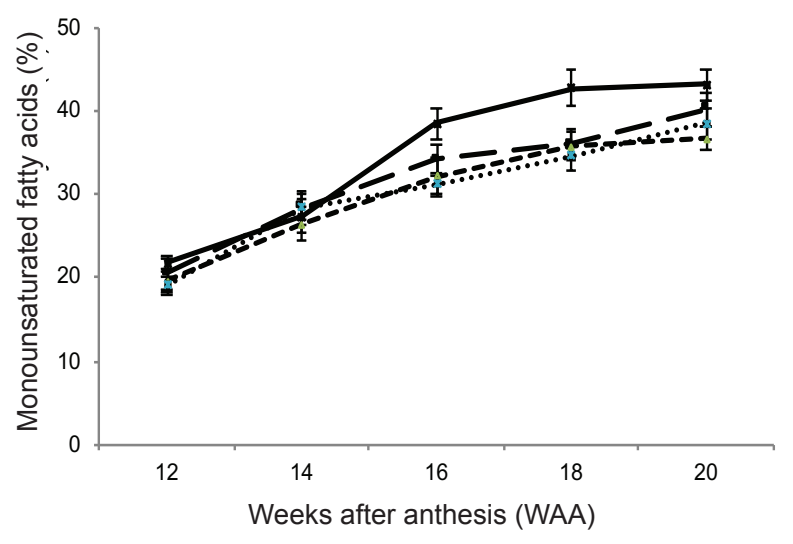

Murphy, 2009). Different edible oil samples were analysed and observed that $47 \%$ SFA are present in palm oil, of which palmitic acid was the dominant fatty acid (Chowdhury et al., 2007). Environment plays a vital role in causing wide variations in fatty acid composition in different crosses (Dierig et al., 2001; Guarrasi et al., 2010).

\section{CONCLUSION}

To conclude, oil synthesis in fruits of UP, DXN, DxG and Palode crosses started at 12 weeks after anthesis and highest oil content $(71.2 \%-79.9 \%)$ was attained at 20 WAA. The ideal time of harvest for four crosses was at 20 WAA, which coincided with highest oil content and maximum fruit weight. SFA was the highest contributor to the fatty acid profile followed by MUFA and PUFA. The MUFA and PUFA composition was highest in DxG cross indicating its superior oil quality under Indian sub-tropical conditions. The variations in fatty acid composition among different oil palm crosses can be exploited for breeding palms possessing higher unsaturated fatty acids, which is an index of superior oil quality.

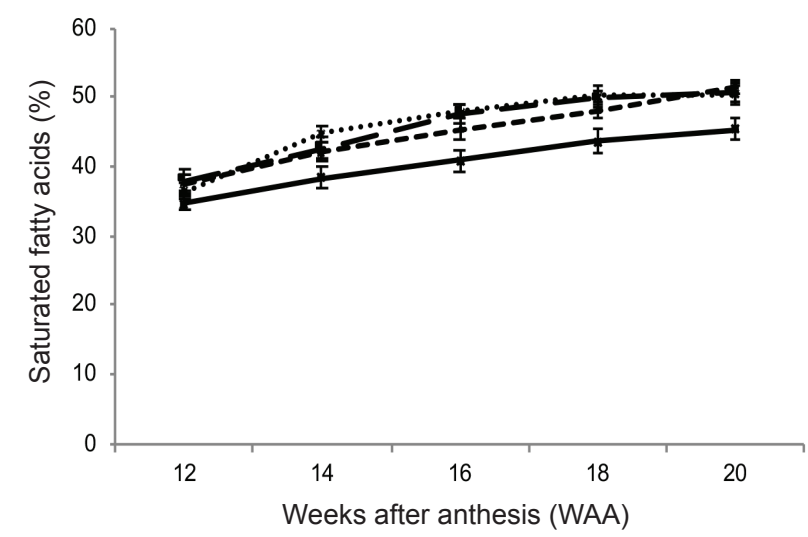

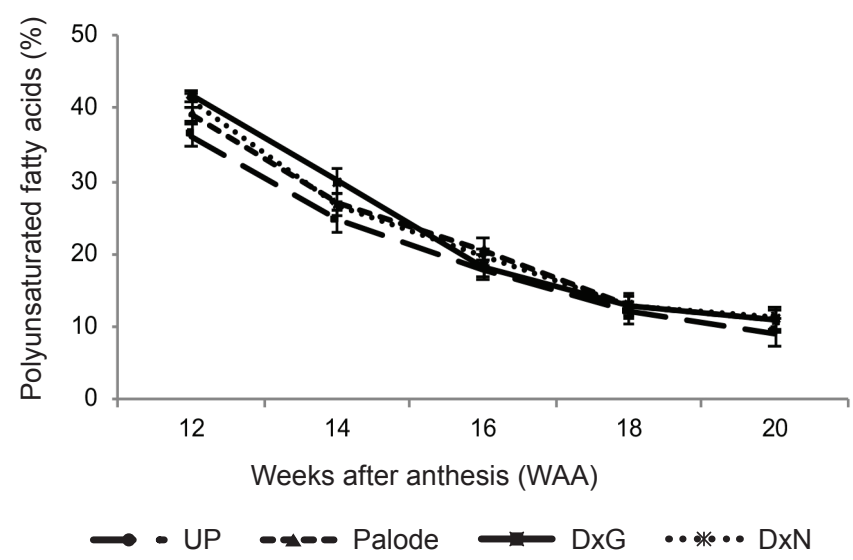

Figure 2. Variations in monounsaturated fatty acids, saturated fatty acids and polyunsaturated fatty acids at different stages of ripening process in oil palm crosses [bars depict standard deviation of mean $(n=9)$ ]. 


\section{REFERENCES}

Alvarado, A and Sterling, F (1998). Seasonal variation in the oil extraction rate in oil palm. ASD Oil Palm Papers, 17: 20-30.

Arulraj, S and Narasimha Rao, B (2012). Oil Palm Area Assessment Report - DOPR. Department of Agriculture and Cooperation, Government of India, New Delhi. p. 27-61.

Aung, W P; Bjertness, E; Htet, A S; Stigun, H; Chongsuvivatwong, V; Soe, P P and Kjollesdal, R (2018). Fatty acid profiles of various vegetable oils and the association between the use of palm oil vs. peanut oil and risk factors for non-communicable diseases in Yangon region, Myanmar. Nutrients, 10(9): 1193.

Azis, A A (1985). The biochemical aspects of ripeness standard. Proc. of the Symposium on Impact of the Pollinating Weevil on the Malaysian Oil Palm Industry. PORIM, Bangi. p. 165-176.

Bafor, M E and Osagie, A U (1986). Changes in lipid class and fatty acid composition during maturation of mesocarp of oil palm (Elaeis guineensis) variety Dura. J. Sci. Food and Agric., 37: 825-832.

Basiron, Y (2005). Palm oil. Bailey's Industrial Oil and Fat Products (Shahidi, F ed.). John Wiley \& Sons Inc., New Jersey, USA. p. 333-429.

Bates, P D; Durrett, T P; Ohlrogge, J B and Pollard, M (2009). Analysis of acyl fluxes through multiple pathways of triacylglycerol synthesis in developing soybean embryos. Plant Physiol., 150: 55-72.

Baud, S and Lepiniec, L (2010). Physiological and developmental regulation of seed oil production. Prog. Lipid Res., 49: 235-249.

Blaak, G (1963). Breeding and inheritance in the oil palm Elaeis guineensis Jacq. Part II. Methods of bunch quality analysis. J. West African Inst. Oil Palm Res., 4: 146-155.

Chen, L; Wang, L; Wang, H; Sun, R and You, L (2018). Identification and characterization of a plastidial $\omega-3$ fatty acid desaturase EgFAD8 from oil palm (Elaeis guineensis Jacq.) and its promoter response to light and low temperature. PLoS One, 13(4): e0196693.

Chowdhury, K; Banu, L A; Khan, S and Latif, A (2007). Studies on the fatty acid composition of edible oil. Bangladesh J. Sci. Ind. Res., 42 (3): 311-316.

Corley, R and Tinker, P B (2003) The Oil Palm. $4^{\text {th }}$ edition. Oxford Blackwell Science Ltd. p. 42.
Dierig, D A; Rayb, D T; Coffelta, T A; Nakayamaa, F S; Leakea, G S and Lorenzc, G (2001). Heritability of height, width, resin, rubber and latex in guayule (Parthenium argentatum). Indust. Crops Prod., 13: 229238.

Ebong, P E; Owu, D U and Isong, E U (1999). Influence of palm oil (Elaeis guineensis) on health. $\mathrm{Pl}$. Foods for Human Nutri., 53: 209-222.

Ganesan, K; Sukalingam, K and Xu, B (2018). Impact of consumption and cooking manners of vegetable oils on cardiovascular diseases - A critical review. Trends in Food Sci. Tech., 71: 132-154.

Guarrasi, V; Mangione, M R; Sanfratello, V; Martorana, V and Bulone, D (2010). Quantification of underivatized fatty acids from vegetable oils by HPLC with UV detection. J. Chromat. Sci., 48: 663668.

Indelicato, S; Bongiorno, D; Pitonzo, R; DiStefano, V; Calabrese, V; Indelicato, S and Avellone, G (2017). Triacylglycerols in edible oils: Determination, characterization, quantitation, chemometric approach and evaluation of adulterations. J. Chromat. A, 1515: 1-16.

Jin, Y; Yuan, Y; Gao, L; Sun, R; Chen, L and Li, D (2017). Characterization and functional analysis of a type 2 Diacylglycerol Acyltransferase (DGAT2) gene from oil palm (Elaeis guineensis Jacq.) mesocarp in Saccharomyces cerevisiae and transgenic Arabidopsis thaliana. Front Plant Sci., 8: 1-10.

Kaida, K Z (1992). A micro strip sensor for determination of harvesting time for oil palm fruits. J. Microwave Power and Electromagnetic Energy, 27(1): $1-9$.

Lieb, V M; Kerfers, M R; Kronmüller, A; Esquivel, P; Alvarado, A; Jiménez, V M; Schmarr, H G; Carle, R; Schweiggert, R M and Steingass, C B (2017). Characterization of mesocarp and kernel lipids from Elaeis guineensis, Elaeis oleifera and their interspecific hybrids. J. Agric. and Food Chemistry, 65: 3617-3626.

Montoya, C; Cochard, B; Flori, A; Cros, D; Lopes, R; Cuellar, T; Espeout, S; Syaputra, I; Villeneuve, P; Pina, M; Ritter, E; Leroy, T and Billotte, N (2014). Genetic architecture of palm oil fatty acid composition in cultivated oil palm (Elaeis guineensis Jacq.) compared to its wild relative E. oleifera (H.B.K) Cortés. PLoS One, 9: e95412. DOI: 10.1371/journal. pone.0095412.

Morrison, W R and Smith, L M (1964). Preparation of methyl esters. J. Lipid Res., 5: 600.

Mozzon, M; Pacetti, D; Lucci, P; Balzano, M and Frega, N G (2013). Crude palm oil from interspecific 
hybrid Elaeis oleifera $\times$ E. guineensis: Fatty acids region distribution and molecular species of glycerides. Food Chemistry, 141: 245-252.

Murphy, DJ (2009). Oil palm: Future prospects for yield and quality improvements. Lipid Tech., 21: 257-260.

Noh, A; Rajanaidu, N; Kushairi, A; Rafil, Y M and Din, A M (2002). Variability in fatty acid composition, iodine value and carotene content in the MPOB oil palm germplasm collection from Angola. J. Oil Palm Res. Vol. 14: 18-23.

Okechalu, J N; Dashen, M; Lar, P M; Okechalu, B and Gushop, T (2011). Industrial oil and fat products. J. Micro. Biotech. Res., 1: 107-112.

Oo, K C; Lee, K B and Ong, A S H (1986). Changes in fatty acid composition of the lipid classes in developing oil palm mesocarp. Phytochemistry, 25: 405-407.

Oo, K C; The, S K and Khor, $\mathrm{H} \mathrm{T}$ and Augustine, S H O (1985). Fatty acid synthesis in the oil palm (Elaeis guineensis): Incorporation of acetate by tissue slices of the developing fruits. Lipids, 20: 205-209.

Opute, F I (1979). Breeding for short-stemmed oil palm in Nigeria: Fatty acids, their significance and characteristics. Ann. Bot., 43: 677-681.

Prada, F; Ivan, M; Ayala-Diaz; Delgado, W; Romero, R R and Heran, M R (2011). Effect of fruit ripening on content and chemical composition of oil from three oil palm cultivars (Elaeis guineensis Jacq.) grown in Columbia. J. Agric. and Food Chem., 59: 10136-10142.

Rajanaidu, N and Tan, B K (1983). Variability of fatty acid composition within bunches in the oil palm, Elaeis guineensis. Oleagineux, 38: 582-583.

Redondo-Cuevas, L; Castellanob, G; Torrensd, F and Raikosa, V (2018). Revealing the relationship between vegetable oil composition and oxidative stability: A multi-factorial approach. J. Food Comp. and Anal., 66: 221-229.

Rincon, S and Martinez, D M (2009). The analysis of lipid properties of oil palm for food industry. Palmas, 30: 11-24.

Salini, B; Kumar, G L M; Mohan Kumar, C and Bhasker, S (1999). Post-harvest biochemical changes in mature oil palm (Elaeis guineensis) fruit pericarp during storage. J. Food Sci. and Tech., 36: 466-468.

Sambanthamurthi, R; Sundram, K and Tan, Y A (2000). Chemistry and biochemistry of palm oil. Prog. in Lipid Res., 39: 507-558.

Sundram, K; Sambanthamurthi, R and Tan, Y A (2003). Palm fruit chemistry and nutrition. Asia Pacific J. Clin. Nutri., 12: 355-362.

Solomons, N W and Orozco, M (2003). Alleviation of vitamin A deficiency with palm fruit and its products. Asia Pacific J. Clin. Nutri., 12: 373-384.

Sun, R; Gao, L; Yu, X; Zheng, Y; Li, D and Wang, X (2016). Identification of a $\Delta 12$ fatty acid desaturase from oil palm (Elaeis guineensis Jacq.) involved in the biosynthesis of linoleic acid by heterologous expression in Saccharomyces cerevisiae. Gene. Elsevier B.V., 592: 21-26.

Suresh, K; Prasanna Lakshmi, R; Kiran Kumar, M and Lakshmi Kantha, D (2013). Growing degree days and reproductive phenology of four oil palm hybrids in India under irrigated conditions. J. Agromet., 15: 108-111.

Ting, N C; Yaakub, Z; Kamaruddin, K; Mayes, S; Massawe, F; Sambanthamurthi, R; Jansen, J; Low, L E T; Ithnin, M; Kushairi, A; Arulandoo, X; Rosli, R; Chan, K L; Amiruddin, N; Sritharan, K; Lim, C C; Nookiah, R; Amiruddin, M D and Singh, R (2016). Fine-mapping and cross-validation of QTLs linked to fatty acid composition in multiple independent interspecific crosses of oil palm. BMC Genomics, 17: 289. DOI: $10.1186 /$ s12864-016-2607-4.

Yordanov, I; Velikova, V and Tsonev, T (2000). Plant responses to drought acclimation and stress tolerance. Photosynthetica, 38: 171-186.

Zaliha, O; Elina, H; Sivaruby, K; Norizzah, A R and Marangoni, A G (2018). Dynamics of polymorphic transformations in palm oil, palm stearin and palm kernel oil characterized by coupled powder XRDDSC. J. Oleo Sci., 67(6): 737-744.

Zulkifli, Y; Rajinder, S; Mohd Din, A; Ting, N C; Rajanaidu, N; Kushairi, A; Musa, B; Mohamad, O and Ismanizan, I (2014). Inheritance of SSR and SNP loci in an oil palm interspecific hybrid backcross (BC2) population. J. Oil Palm Res. Vol. 26: 203-213. 